\title{
ANALISIS PENGARUH KEPUASAN, KUALITAS, DAN EXPERIENTIAL MARKETING TERHADAP WORD OF MOUTH APLIKASI WHATSAPP PADA MAHASISWA FEB UMT
}

\author{
Hendi Eka Sumarga \\ Universitas Muhammadiyah Tangerang \\ hendi_es@yahoo.co.id
}

Keyword
Satisfaction, Quality, Experiential
Marketing, Word Of Mouth

Abstract

This study aims to analyze the effects of satisfaction, quality, and experiential marketing on the creation of word of mouth in the application WhatsApp. This study uses three independent variables of satisfaction, quality, and experiential marketing with one dependent variable ie word of mouth. The use of variables in this study is expected to know how the process occurs and what are the factors driving the creation of word of mouth in WhatsApp application. The sample of this research is user of WhatsApp application from student of Faculty of Economics and Business of University of Muhammadiyah Tangerang. Samples were taken with non probability sampling technique. Data analysis of 160 respondents was done using Structural Equation Modeling (SEM) as an analysis tool using LISREL 8.8 software. Based on the results of data analysis, shows that: experiential marketing variables have a positive influence and the greatest influence on word of mouth WhatsApp applications, satisfaction variable has a positive influence on word of mouth WhatsApp applications. The quality variable has the least positive effect on word of mouth WhatsApp applications.

\section{PENDAHULUAN}

\section{Latar Belakang Masalah}

Kemajuan Teknologi Informasi dan Komunikasi (ICT - Information Communication Technology) memegang peran sangat penting dalam kehidupan manusia modern. Banyak sekali solusi kebutuhan komunikasi dan informasi yang dapat difasilitasi oleh kemajuan ICT ini, salah satunya dengan penggunaan smartphone atau telepon pintar yang terkoneksi dengan internet.

Smartphone sendiri lebih banyak disukai untuk dapat terhubung dengan jaringan internet karena kemampuannya yang canggih layaknya komputer portable yang pintar dan multifungsi. Berbagai variasi aplikasi untuk smartphonebanyak ditawarkan pada para pengguna, terutama pada mereka yang menggunakan smartphone dengan sistem operasional android dan iOS. Banyak aplikasi-aplikasi yang bermanfaat dan gratis ditawarkan untuk memenuhi kebutuhan informasi dan komunikasi masyarakat. Salah satu aplikasi yang tanggap akan kebutuhan masyarakat pengguna smartphone ini adalah aplikasi pesan instan WhatsApp Messenger.

Data berikut memperlihatkan popularitas WhatsApp di dunia sebagai aplikasi pesan instan paling banyak dimiliki dan digunakan oleh para pengguna smartphone di dunia yang mengaktifkan data selulernya. 


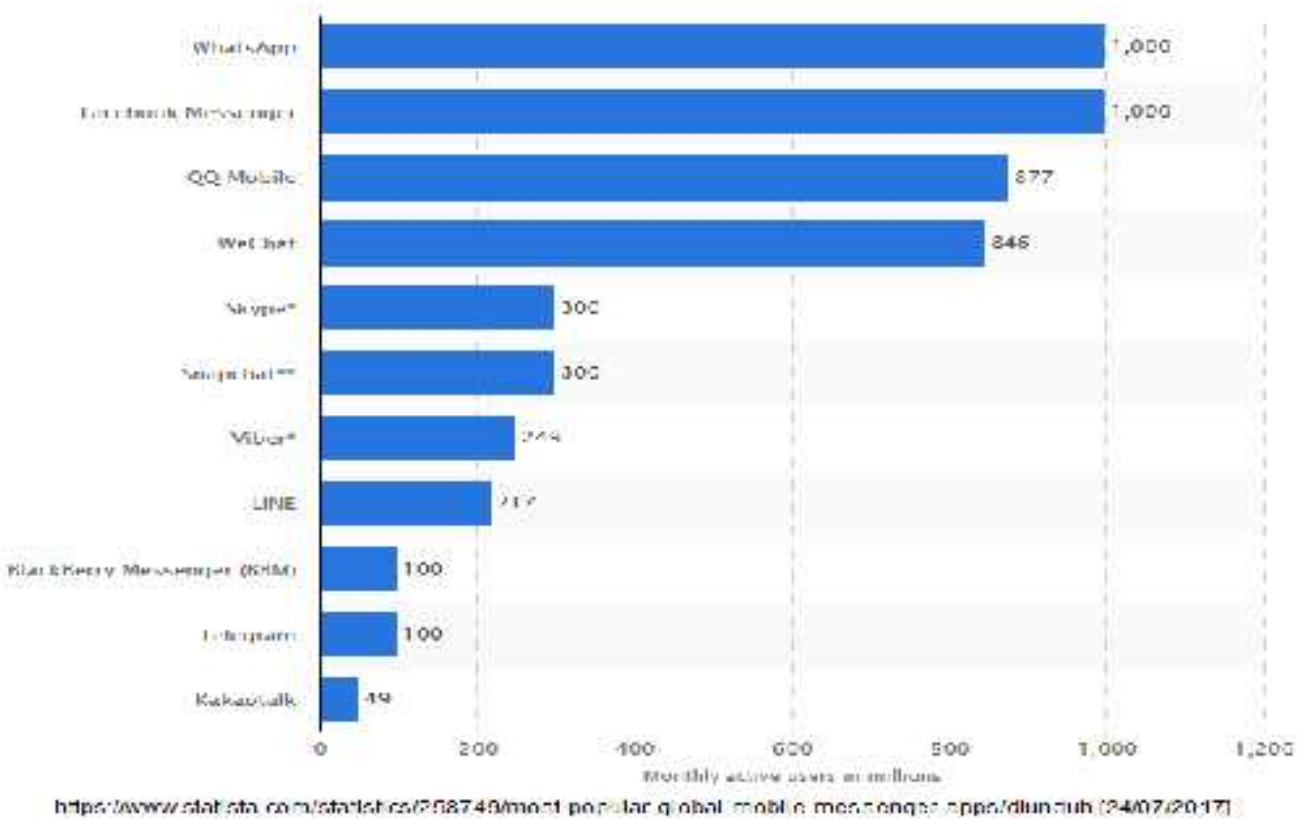

Al Hamdani dan Dawood Salim (20I3) meneliti tentang metode belajar mahasiswa di Universitas Sohar, Oman. Hasil penelitian tersebut salah satunya menyebutkan aplikasi WhatsApp sebagai salah satu aplikasi obrolan yang paling sering digunakan oleh para mahasiswa sebagai sarana berbagi informasi perkuliahan, sarana berbagi konten multimedia dalam berbagai format dan ukuran, media yang ekonomis, dan sangat membantu proses mahasiswa untuk saling bekerjasama dan berkolaborasi.

$\mathrm{Hal}$ ini serupa dengan hasil penelitian Ahad dan Lim (2014) terhadap anak-anak muda khususnya para mahasiswa di Universiti Brunei Darussalam yang menyatakan bahwa aplikasi WhatsApp sebagai aplikasi komunikasi yang 'nyaman' untuk digunakan dalam kegiatan mereka sehari-hari, baik untuk tujuan personal maupun untuk tujuan kelompok.

Walaupun demikian, ada beberapa kelemahan dari aplikasi Whatsapp mengenai gangguan dan eksposur pesan-pesan yang tidak beraturan (spam), yang mungkin disebabkan adanya kemudahan aplikasi ini untuk dapat mengirim pesan hanya dengan mengetahui nomor kontak pemilik akun tanpa harus melalui proses verifikasi ataupun persetujuan dari pemilik akun bersangkutan.

Salah satu kunci sukses mengapa WhatsApp sedemikian populer dan memiliki banyak pengguna ialah karena peran penggunanya sendiri yang merekomendasikan WhatsApp kepada temannya yang belum menjadi pengguna. Cara berkomunikasi seperti ini disebut dengan Word Of Mouth. Word Of Mouth atau WOM, adalah suatu komunikasi interpersonal tentang produk diantara pembeli dan orang-orang di sekitarnya (Kotler, 200I). Word Of Mouth bahkan memiliki tingkat dampak yang lebih besar dibandingkan dengan informasi tertulis sebagaimana diungkap oleh Herr (199I).

Efek dari WOM ini sangat besar, bahkan banyak pemasar yang telah memanfaatkannya. WOM memiliki efek yang kuat dan besar karena berasal dari sumber yang terpercaya, pengaruhnya bahkan diakui lebih besar dari pengaruh iklan Above The Line (ATL) di televisi (Fahima, 2007). Adapun variabel-variabel yang mempengaruhi terciptanya WOM diantaranya ialah kepuasan pelanggan (Priharmoko, 2004), kualitas produk (Tjiptono, 2006) dan experiential marketing seperti yang diungkapkan oleh Thomas (2004). Ke tiga variabel ini sangat penting dan menentukan sejauh mana keberhasilan WOM yang diinginkan perusahaan. Ke tiga variabel ini akan menentukan WOM seperti apa yang akan disebar, apakah positif atau negatif (Priharmoko, 2004).

Kepuasan pelanggan adalah salah satu tujuan utama dari tiap perusahaan. Pelanggan yang puas berarti jaminan kesuksesan dan keberhasilan. Engel et al (2006) mengemukakan konsep bahwa yang dimaksud dengan kepuasan pelanggan adalah evaluasi purna beli dimana alternatif yang dipilih sekurang-kurangnya sama atau melampaui harapan pelanggan, sedangkan ketidakpuasan timbul apabila hasil tidak memenuhi harapan. 
Oliver dalam Peter dan Olson (2002) menyatakan bahwa kepuasan adalah rangkuman kondisi psikologis yang dihasilkan ketika emosi yang mengelilingi harapan yang tidak cocok dilipatgandakan oleh perasaan-perasaan yang terbentuk dalam konsumen tentang pengalaman pengkonsumsian. Kepuasan konsumen adalah salah satu bahasan penting dalam dunia pemasaran. Jika konsumen merasa puas, mereka akan membeli dan terus menggunakannya serta memberitahukan kepada orang lain akan produk tersebut (Word of Mouth). Sebaliknya, jika mereka tidak puas, mereka cenderung beralih merek, dan mengajukan keberatan pada produsen, pengecer dan menceritakannya pada orang lain (Peter dan Olson, 2002). Wagner dan Rydstrom (200I) mendefinisikan kepuasan pelanggan sebagai pemenuhan kesenangan dan suatu keadaan atau pengaruh yang positif.

Kualitas produk merupakan salah satu hal yang harus diperhatikan karena memiliki urgensi yang sangat tinggi dan berkontribusi besar terhadap komunikasi Word of Mouth, retensi pelanggan, pembelian ulang, loyalitas, bahkan pangsa pasar (Tjiptono, 2006). Sementara Buzell \& Gale, dalam Tjiptono (2006) mengemukakan bahwa kualitas berhubungan dengan pangsa pasar, reputasi perusahaan dan kemampuan menetapkan premium harga.

Experiential Marketing adalah pemasaran produk dengan menggunakan dan merangsang sisi-sisi emosional konsumen yang akan menghasilkan berbagai pengalaman (Schmitt, 1999). Schmitt (1999) menyatakan bahwa dalam memilih produknya konsumen bukan hanya dipengaruhi oleh faktor-faktor rasional saja tetapi juga faktor-faktor emosional. Faktorfaktor emosional ini yang ingin dieksplorasi lebih jauh dengan konsep Experiential Marketing.

\section{Rumusan Masalah} adalah:

Rumusan masalah dalam penelitian ini

I. Bagaimana Kepuasan berpengaruh terhadap terciptanya Word Of Mouth untuk aplikasi WhatsApp?

2. Bagaimana Kualitas Produk berpengaruh terhadap terciptanya Word Of Mouth untuk aplikasi WhatsApp?

3. Bagaimana Experiential Marketing berpengaruh terhadap terciptanya Word Of Mouth untuk aplikasi WhatsApp?

\section{TINJAUAN PUSTAKA}

\section{WhatsApp}

Karakteristik aplikasi pesan instan (Instant Messenger) WhatsApp adalah bahwa ia memiliki mekanisme login yang sangat praktis. Kita hanya perlu menyimpan nomor ponsel seseorang di perangkat smartphone kita dan secara otomatis jika kita telah mengunduh aplikasi WhatsApp di smartphone kita yang terkoneksi dengan internet, nomor-nomor yang sudah berada dalam kontak akan terhubung dengan kontakkontak tersebut yang juga sama-sama menggunakan aplikasi WhatsApp.

Dan lagi, aplikasi ini bebas iklan yang membuat pengguna aplikasi tidak terganggu dengan serbuan iklan-iklan yang biasanya ditemui dalam aplikasi-aplikasi pesan instan lainnya. Selain itu, aplikasi ini juga tidak meminta pengguna untuk memberikan data-data pribadinya ketika mengaktivikasikan akun WhatsApp-nya, sehingga pengguna tidak khawatir jika data-data pribadinya akan disalahgunakan.

\section{Word of Mouth}

Brown et al (2005) mendefinisikan WOM sebagai informasi tentang suatu target objek yang dipindahkan dari satu individu ke individu lain yang dilakukan secara langsung atau tidak langsung melalui media komunikasi. Sedangkan menurut Word Of Mouth Marketing Association (WOMMA) WOM adalah usaha pemasaran yang memicu konsumen untuk membicarakan, mempromosikan, merekomendasikan hingga menjual merek kepada calon konsumen lainnya.

Adapun Kotler (200I) mendefinisikan WOM sebagai suatu komunikasi interpersonal tentang produk diantara pembeli dan orangorang yang ada di sekitarnya. Sementara Harrisson dan Walker (200I) mendefinisikan WOM sebagai informasi informal dari satu orang ke orang lain antara seorang pembawa pesan nonkomersial tentang apa yang dirasanya dengan penerima terhadap suatu produk, organisasi, jasa, dan merek.

\section{Kepuasan Pelanggan}

Engel et al (2006) mendefinisikan kepuasan pelanggan sebagai evaluasi purna beli dimana alternatif yang dipilih sekurangkurangnya sama atau melampaui harapan pelanggan, sedang ketidak puasan timbul apabila hasil tidak memenuhi harapan. Sedangkan Kotler (200I) mengemukakan bahwa kepuasan pelanggan ialah tingkat perasaan seseorang 
setelah membandingkan kinerja atau hasil yang ia rasakan dengan dibandingkan harapannya.

Kepuasan atau ketidakpuasan pelanggan adalah respon pelanggan terhadap evaluasi ketidasesuaian (disconfirmation) yang dirasakan antara harapan sebelumnya dan kinerja aktual produk yang dirasakan setelah pemakaiannya (Tjiptono, 2006). Tse dan Wilton dalam Tjiptono (2006) mendefinisikan kepuasan pelanggan sebagai respon pelanggan terhadap evaluasi ketidaksesuaian yang dipersepsikan antara harapan awal sebelum pembelian dan kinerja actual produk yang dipersepsikan setelah pemakaian atau konsumsi barang bersangkutan.

\section{Kualitas}

Menurut Feigenbaum (1992) Kualitas adalah kepuasan pelanggan sepenuhnya (full customer satisfaction). Suatu produk dikatakan berkualitas apabila dapat memberi kepuasan sepenuhnya kepada konsumen, yaitu sesuai dengan apa yang diharapkan konsumen atas suatu produk. Adapun menurut Garvin (1988) Kualitas adalah suatu kondisi dinamis yang berhubungan dengan produk, manusia/tenaga kerja, proses dan tugas, serta lingkungan yang memenuhi atau melebihi harapan pelanggan atau konsumen.

Konsep kualitas itu sendiri sering dianggap sebagai ukuran relatif kebaikan suatu produk atau jasa.Pelayanan atau jasa merupakan pemberian suatu kinerja atau tindakan tak kasatmata dari satu pihak kepada pihak lain (Rangkuti, 2002). Goesth dan Davis yang dikutip Tjiptono, mengemukakan bahwa kualitas diartikan sebagai suatu kondisi dinamis dimana yang berhubungan dengan produk, jasa, manusia, proses dan lingkungan yang memenuhi atau melebihi harapan (Tjiptono, 2006).

\section{Experiential Marketing}

Kartajaya (2002) mengemukakan bahwa konsep pemasaran berbasis pengalaman (Experiential Marketing) adalah pemasaran tingkat keempat. Pemasaran berbasis pengalaman adalah pemasaran dengan pendekatan penciptaan produk atau jasa yang mencoba menyentuh panca indra konsumen. Menyentuh hati, dan merangsang pikiran konsumen sehingga hal tersebut dapat menciptakan pengalaman di dalam diri konsumen yang akhirnya menjadi sesuatu yang dapat dikenang dan diceritakan kepada orang-orang terdekat (Schmitt, 1999).

Experiential marketing merujuk pada pengalaman nyata pelanggan terhadap brand/product/service untuk meningkatkan penjualan/sales dan brand image/awareness. Experiential marketing adalah lebih dari sekedar memberikan informasi dan peluang pada pelanggan untuk memperoleh pengalaman atas keuntungan yang didapat dari produk atau jasa itu sendiri tetapi juga membangkitkan emosi dan perasaan yang berdampak terhadap pemasaran, khususnya penjualan (Andreani, 2007)

\section{Kerangka Pemikiran}

Beberapa penelitian menyebutkan, bahwa terdapat hubungan antara pengalaman baik positif ataupun negatif dari pemakaian suatu produk barang atau jasa dengan kepuasan konsumen, yang akhirnya dapat mendorong WOM baik positif atau negatif (Priharmoko, 2004). Tjiptono (2006) menegaskan bahwa WOM dapat dipicu oleh antara lain kepuasan pelanggan. Zeithaml (1990) mengemukakan bahwa harapan pelanggan muncul karena beberapa hal, yakni Word Of Mouth, kebutuhan pribadi, dan pengalaman.

$\begin{array}{lll}\text { (1998) suatu perusahaan dalam } & \text { dalitas } \\ \text { mempertimbang-kan } & \text { penerapan }\end{array}$
pelayanan berhubungan dengan bagaimana perusahaan tersebut memposisikan dirinya dalam memahami nilai dasar pelanggan yang tercermin pada konsep kepuasan pelanggan yang kuat. Hasil penelitiannya menyatakan kualitas layanan berpengaruh secara positif terhadap loyalitas dan WOM positif. Parasuraman et al (1995) mengemukakan bahwa Kualitas layanan berhubungan dengan loyalitas konsumen dan komunikasi WOM yang positif. Kualitas pelayanan berpengaruh positif terhadap komunikasi WOM (Harrison-Walker, 200I).

Sebagai bagian penting dari pendekatan pemasaran modern, Experiential Marketing diyakini dapat mendorong terciptanya Word Of Mouth (WOMMA, 2003). Nuys (2005) juga mengemukakan bahwa Experiential Marketing dapat menciptakan Word of Mouth. Sementara Thomas (2004) menyatakan bahwa Experiential Marketing adalah salah satu alat untuk menciptakan Word of Mouth.

Berdasarkan uaraian di atas maka dirumuskan kerangka konseptual sebagai berikut: 


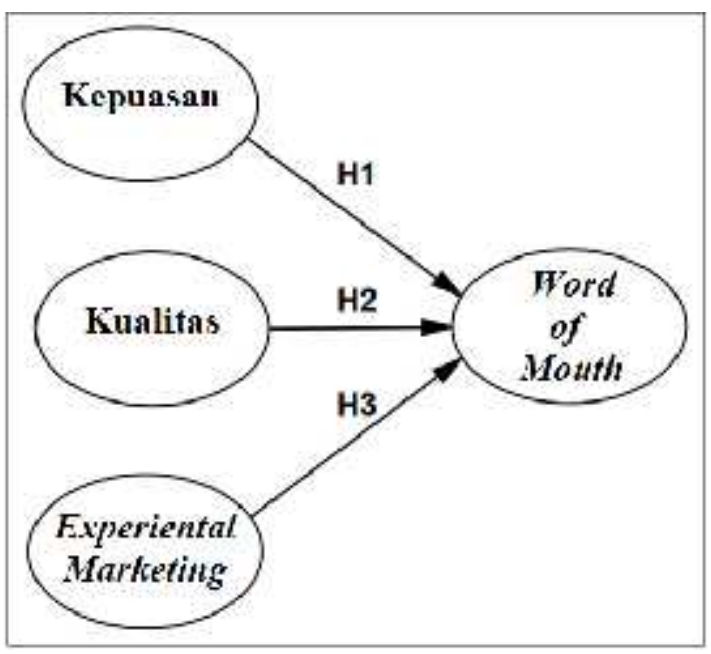

Gambar I. Kerangka Konseptual

\section{Hipotesis Penelitian}

HI: Terdapat pengaruh positif Kepuasan terhadap terciptanya Word Of Mouth.

H2: Terdapat pengaruh positif Kualitas terhadap terciptanya Word Of Mouth.

H3: Terdapat pengaruh positif Experiential Marketing terhadap terciptanya Word of Mouth.

\section{METODE PENELITIAN}

\section{Jenis Penelitian}

Jenis peneltian yang digunakan dalam penelitian ini adalah jenis penelitian verifikatif. Dengan menggunakan jenisn penelitian ini akan diketahui pengaruh yang signifikan antara variabel yang diteliti sehingga menghasilkan kesimpulan.

\section{Tempat dan Waktu Penelitian}

Lokasi penelitian ini dilakukan pada Universitas Muhammadiyah Tangerang (UMT). Waktu penelitian selama I bulan (Maret 20I7) dan dilakukan dengan menyebarkan angket atau kuisioner.

\section{Populasi dan Sampel}

Populasi adalah gabungan dari seluruh elemen yang berbentuk peristiwa, hal atau orang yang memiliki karakteristik yang serupa yang menjadi pusat perhatian seorang peneliti karena itu dipandang sebagai salah satu semesta penelitian (Ferdinand, 2006). Populasi dalam penelitian ini adalah seluruh mahasiswa Fakultas Ekonomi dan Bisnis UMT angkatan 2013-20I6.

Penentuan sampel responden dalam penelitian ini menggunakan non probability sampling, yaitu teknik pengambilan sampel yang tidak memberi peluang/ kesempatan sama bagi setiap unsur atau anggota populasi untuk dipilih menjadi sampel. Metode yang digunakan dalam pengambilan sampel ini adalah mengambil purposive sampling yaitu peneliti menggunakan pertimbangan sendiri secara sengaja dalam memilih anggota populasi yang dianggap dapat memberikan informasi yang diperlukan atau unit sampel yang sesuai dengan kriteria tertentu yang diinginkan peneliti yaitu mahasiswa fakultas ekonomi dan bisnis yang menggunakan aplikasi WhatsApp.

Bentler dan Chou (1987) dalam Wijanto (2008) menyarankan bahwa rasio sampel paling rendah per variabel teramati yaitu 5 responden, sehingga dapat mencukupi untuk distribusi normal saat sebuah variabel laten memiliki beberapa variabel teramati (indikator). Berdasarkan hal tersebut, maka ukuran sampel penelitian ini dengan menggunakan estimasi maximum likelihood yaitu sebanyak 160 responden $(10 \times 16$ variabel teramati).

\section{Metode Pengumpulan Data}

Metode pengumpulan data yang digunakan dalam penelitian ini adalah metode kuisioner. Kuisioner adalah sejumlah pertanyaan tertulis yang digunakan untuk memperoleh informasi dari responden dalam arti laporan tentang halhal yang ia ketahui (Arikunto, 2006).

Survei mengumpulkan data primer diperoleh dengan cara membagikan sejumlah kuisioner kepada mahasiswa fakultas ekonomi dan bisnis. Angket tersebut diberikan kepada para responden dan kemudian responden akan mengisinya sesuai dengan pendapat dan persepsi responden.

Pernyataan-pernyataan dalam kuesioner dibuat dengan menggunakan skala $\mathrm{I}-10$ untuk mendapatkan data yang bersifat interval dan diberi skor atau nilai. Penggunaan skala I-I0 (skala genap) untuk menghindari jawaban responden yang cenderung memilih jawaban di tengah, sehingga akan menghasilkan respon yang mengumpul di tengah (grey area). Berikut kategori pengukurannya:

Sangat tidak setuju/buruk

Sangat setuju/ baik

\begin{tabular}{|l|l|l|l|l|l|l|l|l|l|}
\hline $\mathrm{I}$ & 2 & 3 & 4 & 5 & 6 & 7 & 8 & 9 & 10 \\
\hline
\end{tabular}

\section{Operasional Variabel}

Menurut Supomo dan Indriantoro (2002) operasionalisasi variabel adalah penentuan konstruk sehingga menjadi variabel yang dapat diukur. 
Operasionalisasi variabel diperlukan untuk menentukan jenis, indikator, serta skala dari variabel-variabel yang terkait dalam penelitian, sehingga pengujian hipotesis dengan alat bantu statistik dapat dilakukan secara benar sesuai dengan judul penelitian. Variabel-variabel yang akan diukur dalam penelitian ini yaitu:

I. Variabel bebas atau independen

Menurut Sugiyono (20/3), variabel bebas adalah variabel yang akan mempengaruhi atau yang menjadi sebab perubahannya atau timbulnya variabel dependen (terikat). Variabel independen pada penelitian ini adalah Kepuasan, Kualitas dan Experiential Marketing.

2. Variabel terikat atau dependen Menurut Sugiyono (2013), variabel terikat adalah variabel yang dipengaruhi atau yang menjadi akibat karena adanya variabel bebas. Variabel dependen dalam hal ini adalah Word of Mouth.

Variabel dan indikator yang digunakan dalam penelitian ini dijelaskan dalam tabel I berikut ini:

Tabel I. Variabel dan Indikator Penelitian

\begin{tabular}{|c|c|}
\hline Variabel & Indikator \\
\hline $\begin{array}{l}\text { Kepuasan } \\
\left(\xi_{1}\right)\end{array}$ & $\begin{array}{ll}- & \text { Kepuasan keseluruhan }\left(X_{1}\right) \\
- & \text { Kepuasan hasil yang didapat } \\
& \left(\mathrm{X}_{2}\right) \\
\text { - } & \text { Kepuasan perbandingan } \\
& \text { harapan dan kenyataan }\left(\mathrm{X}_{3}\right) \\
\text { Sumber: Kotler }(2001) \text {, Engel et } \\
\text { all }(2006)\end{array}$ \\
\hline $\begin{array}{l}\text { Kualitas } \\
\left(\xi_{2}\right)\end{array}$ & $\begin{array}{ll}\text { - } & \text { Aksesabilitas }\left(X_{4}\right) \\
\text { - } & \text { Reputasi }\left(X_{5}\right) \\
\text { - } & \text { Keamanan }\left(X_{6}\right) \\
\text { - } & \text { Fungsionalitas }\left(X_{7}\right) \\
\text { Sumber: Tjiptono }(2006) \\
\end{array}$ \\
\hline $\begin{array}{l}\text { Experiental } \\
\text { Marketing } \\
\left(\xi_{3}\right)\end{array}$ & $\begin{array}{ll}- & \text { Sense }\left(X_{8}\right) \\
- & \text { Feel }\left(X_{9}\right) \\
- & \text { Act }\left(X_{10}\right) \\
\text { - } & \text { Think }\left(X_{11}\right) \\
\text { - } & \text { Relate }\left(X_{12}\right) \\
\text { Sumber: Schmitt (1999) }\end{array}$ \\
\hline $\begin{array}{l}\text { Word of } \\
\text { Mouth } \\
\left(\eta_{1}\right)\end{array}$ & $\begin{array}{ll}\text { - } & \text { Rekomendasi }\left(\mathrm{Y}_{1}\right) \\
\text { - } & \text { Pengaruh normatif }\left(\mathrm{Y}_{2}\right) \\
\text { - } & \text { Talking }\left(\mathrm{Y}_{3}\right) \\
\text { - } & \text { Brand Recalling }\left(\mathrm{Y}_{4}\right) \\
\text { Sumber: Brown et al }(2005), \\
\text { Harrison-Walker }(200 \mathrm{I})\end{array}$ \\
\hline
\end{tabular}

\section{Metode Analisis}

Karena dalam penelitian ini menggunakan indikator untuk mengukur setiap konstruknya, dan juga model pengukuran bersifat struktural, maka pendekatan dalam permodelan yang digunakan dalam penelitian ini adalah Structural Equation Modelling (SEM) dengan bantuan perangkat lunak LISREL.

Langkah-langkah analisis dengan metode Structural Equation Modelling (SEM) secara ringkas diuraikan sebagai berikut:

I. Merancang persamaan struktural (structural equation)

Perancangan ini didasarkan pada rumusan masalah atau hipotesis penelitian.untuk menyatakan hubungan kausalitas antara berbagai konstruk.

2. Merancang model pengukuran (measurement model)

Perancangan model ini digunakan untuk mengetahui validitas dan reliabilitas yang menghubungkan indikator dengan variabel latennya.

3. Konstruksi Diagram Jalur Penelitian

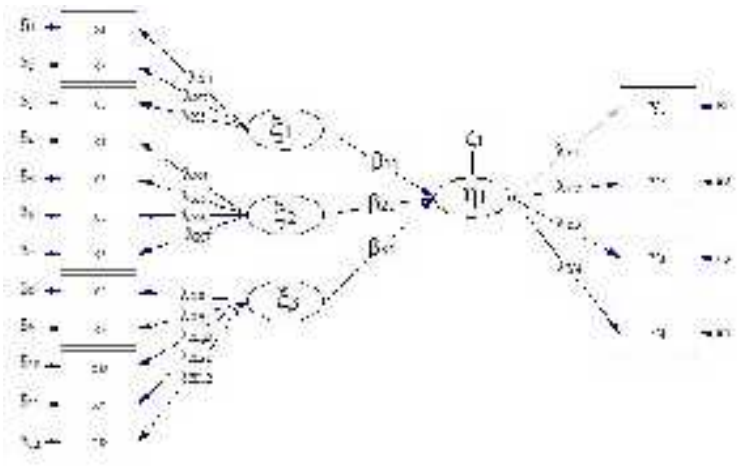

\section{Gambar 2. Konstruksi Diagram Jalur Penelitian}

Keterangan:

$\xi_{1}:$ Kepuasan

$\xi_{2}:$ Kualitas

$\xi_{3}:$ Experiential Marketing

$\eta_{1}:$ Word of Mouth

$X_{1}-X_{3}:$ Indikator Kepuasan

$\mathrm{X}_{4}-\mathrm{X}_{7}$ : Indikator Kualitas

$X_{8}-X_{12}$ : Indikator Experiential Marketing

$Y_{1}-Y_{4}$ : Indikator Word of Mouth

$\beta_{11}$ : Koefisien Kepuasan terhadap Word of Mouth

$\beta_{21}$ : Koefisien Kualitas terhadap Word of Mouth

$\beta_{31}$ : Koefisien Experiential Marketing terhadap Word of Mouth

$\lambda_{x_{1}}-\lambda_{x_{3}} \quad$ : Koefisien Kepuasan

$\lambda_{x_{4}}-\lambda_{x_{7}} \quad:$ Koefisien Kualitas 


$$
\begin{array}{ll}
\lambda_{X 8}-\lambda_{X 12} & \begin{array}{l}
: \text { Koefisien Experiential } \\
\text { Marketing }
\end{array} \\
\lambda_{Y 1}-\lambda_{Y 4}: \begin{array}{l}
: \text { Koefisien Word of Mouth } \\
\zeta_{1}
\end{array} & \text { Galat Word of Mouth } \\
\delta_{1}-\delta_{3}: \text { Galatindikator Kepuasan } \\
\delta_{4}-\delta_{7}: \text { Galat indikator Kualitas } \\
\delta_{11}-\delta_{14}: \text { Galat indikator Experiential } \\
\\
\quad \text { Marketing } \\
\varepsilon_{1}-\varepsilon_{4}: \text { Galat indikator Word of Mouth }
\end{array}
$$

4. Konversi Diagram Jalur ke Sistem Persamaan

I) Structural Model

Structural model menentukan spesifikasi hubungan antara konstruk satu dengan konstruk lainnya.

$$
\begin{aligned}
& \eta_{1}=\gamma_{11} \xi_{1}+\gamma_{21} \xi_{2}+\gamma_{31} \xi_{3}+\zeta_{1} \\
& \eta_{2}=\beta_{12} \eta_{1}+\zeta_{2}
\end{aligned}
$$

2) Measurement Model

Measurement model menentukan spesifikasi hubungan antara konstruk dan indikatornya.

$X_{1}=\lambda x_{1} \xi_{1}+\delta_{1}$

$X_{2}=\lambda x_{2} \xi_{1}+\delta_{2}$

$X_{3}=\lambda x_{3} \xi_{1}+\delta_{3}$

$X_{4}=\lambda x_{4} \xi_{2}+\delta_{4}$

$X_{5}=\lambda x_{5} \xi_{2}+\delta_{5}$

$X_{6}=\lambda x_{6} \xi_{2}+\delta_{6}$

$X_{7}=\lambda x_{7} \xi_{2}+\delta_{7}$

$X_{8}=\lambda x_{8} \xi_{3}+\delta_{8}$

$X_{9}=\lambda x_{9} \xi_{3}+\delta_{9}$

$X_{10}=\lambda x_{10} \xi_{3}+\delta_{10}$

$x_{11}=\lambda x_{11} \xi_{3}+\delta_{11}$

$X_{12}=\lambda x_{12} \xi_{3}+\delta_{12}$

$Y_{1}=\lambda y_{1} \eta_{1}+\varepsilon_{1}$

$Y_{2}=\lambda y_{2} \eta_{1}+\varepsilon_{2}$

\begin{tabular}{|c|c|}
\hline $\begin{array}{l}\text { Goodness of Fit } \\
\text { Index }\end{array}$ & Cut-of Value \\
\hline$\chi^{2}-$ Chi-square & $\begin{array}{c}\chi_{\text {Hitung }}^{2} \text { diharapkan kecil } \\
\text { dari } \chi_{\text {Tabel }}^{2}\end{array}$ \\
\hline $\begin{array}{l}\text { Significancy } \\
\text { probability }\end{array}$ & $\geq 0,05$ \\
\hline RMSEA & $<0,08$ \\
\hline GFI & $\geq 0,90$ \\
\hline
\end{tabular}

$Y_{3}=\lambda y_{3} \eta_{1}+\varepsilon_{3}$

$Y_{4}=\lambda Y_{4} \eta_{2}+\varepsilon_{4}$

5. Evaluasi Kriteria Goodness of Fit

Uji kesesuaian model dilakukan dengan menggunakan beberapa ukuran kesesuaian model (Goodness of Fit).Indeks-indeks yang digunakan untuk menguji kelayakan sebuah model adalah sebagai berikut :

Tabel 2. Indeks Pengujian Kelayakan Model(Goodness of Fit Index)

\begin{tabular}{|c|c|}
\hline AGFI & $\geq 0,90$ \\
\hline CMIN/DF & $<2,00$ \\
\hline TLI & $\geq 0,95$ \\
\hline CFI & $\geq 0,95$ \\
\hline
\end{tabular}

Sumber: Ferdinand (2006)

6. Uji Hipotesis

Rancangan uji hipotesis dalam penelitian ini disajikan berdasarkan tujuan penelitian. Tingkat kepercayaan yang digunakan adalah $95 \%$, sehingga tingkat signifikansi sebesar $(\alpha)$ $=5 \%=0,05$. Dan menghasilkan nilai t-tabel sebesar I,96.

Sehingga:

- Jika nilai t-hitung lebih kecil dari nilai ttabel (t-hitung $<\mathrm{I}, 96$ ), maka $\mathrm{H}_{0}$ diterima dan $\mathrm{H}_{\mathrm{a}}$ ditolak.

- Jika nilai t-hitung lebih besar dari nilai ttabel (t-hitung > I,96), maka $\mathrm{H}_{0}$ ditolak dan $\mathrm{H}_{\mathrm{a}}$ diterima

\section{HASIL PENELITIAN DAN PEMBAHASAN}

\section{Hasil Penelitian}

Dalam penelitian ini, langkah pertama yang dilakukan adalah mengevaluasi hubungan antara variabel dengan indikatornya. Evaluasi ini meliputi indikator validitas, reliabilitas konstruk, dan nilai average variance extracted (AVE). Indikator validitas dapat dilihat dari nilai loading factor. Bila nilai loading factor suatu indikator lebih dari 0,70; maka dapat dikatakan valid. Sebaliknya, bila nilai loading factor kurang dari 0,70; maka harus dikeluarkan dari model.

Berikut adalah evaluasi model pengukuran terhadap indikator Kepuasan (KEPUASAN), Kualitas (KUALITAS), Experiential Marketing (EM) dan Word of Mouth(WOM).

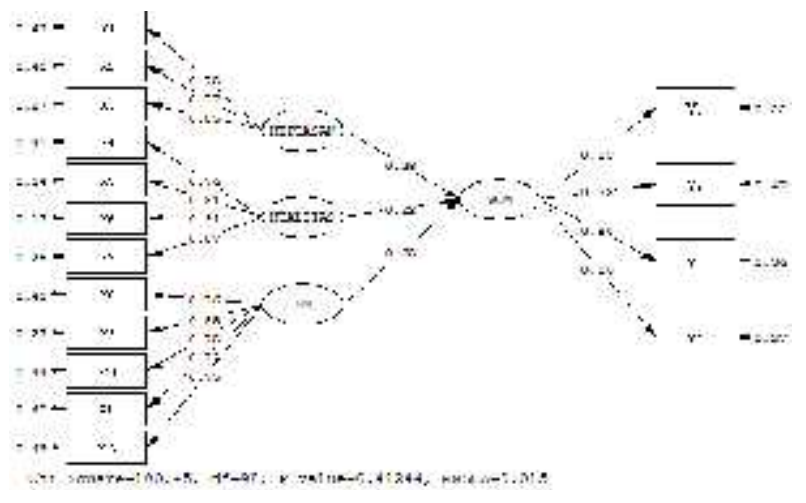

Gambar 3. Basic Model (Standardized Solutions) 
Tabel 3.Nilai Loading Factor Indikator

\begin{tabular}{|l|c|}
\hline \multicolumn{1}{|c|}{ Indikator } & $\begin{array}{c}\text { Loading } \\
\text { Factor }\end{array}$ \\
\hline XI <- Kepuasan (KEPUASAN) & 0,75 \\
\hline X2 <- Kepuasan (KEPUASAN) & 0,77 \\
\hline X3 <- Kepuasan (KEPUASAN) & 0,85 \\
\hline X4 <- Kualitas (KUALITAS) & 0,76 \\
\hline X5 <- Kualitas (KUALITAS) & $0,8 \mathrm{I}$ \\
\hline X6 <- Kualitas (KUALITAS) & 0,9 I \\
\hline X7 <- Kualitas (KUALITAS) & 0,87 \\
\hline X8 <-Experiential Marketing (EM) & 0,76 \\
\hline X9 <-Experiential Marketing (EM) & 0,85 \\
\hline XI0<-Experiential Marketing (EM) & 0,75 \\
\hline XII <-Experiential Marketing (EM) & 0,72 \\
\hline XI2 <-Experiential Marketing (EM) & 0,75 \\
\hline YI <-Word of Mouth (WOM) & 0,89 \\
\hline Y2 <-Word of Mouth (WOM) & 0,73 \\
\hline Y3 <-Word of Mouth (WOM)) & 0,80 \\
\hline Y4 <-Word of Mouth (WOM) & 0,86 \\
\hline
\end{tabular}

Sumber: Data primer diolah (2017)

Berdasarkan Gambar 3 dan Tabel 3 menunjukkan semua indikator memiliki loading factor $>0,70$ menunjukkan semua indikator tersebut valid

Evaluasi selanjutnya adalah pemeriksaan reliabilitas konstruk yang menggunakan dua ukuran (Hair dkk., 2006), yaitu:

(I) Construct RealibilityMeasure (CR), dengan persyaratan nilai $C R \geq 0,70$.

(2) Average Variance ExtractedMeasure (AVE), dengan persyaratan nilai $A V E \geq 0,50$.

Berdasarkan hasil perhitungan didapatkan nilai Construct Realibility (CR) dan nilai Average Variance Extracted (AVE) seperti ditunjukkan pada Tabel 4.

Tabel 4.Nilai Construct Realibility (CR) dan Average Variance Extracted (AVE)

\begin{tabular}{|l|c|c|}
\hline \multicolumn{1}{|c|}{ Konstruk } & CR & AVE \\
\hline Kepuasan (KEPUASAN) & 0,85 & 0,73 \\
\hline Kualitas (KUALITAS) & 0,82 & 0,83 \\
\hline Experiential Marketing (EM) & 0,77 & 0,71 \\
\hline Word of Mouth (WOM) & 0,82 & 0,80 \\
\hline
\end{tabular}

Sumber: Data primer diolah (2017)

Berdasarkan Tabel 4, semua nilai construct reliability $(C R) \geq 0,70$; berarti reliabilitas konstruk terpenuhi, dan juga semua nilai average variance extracted $(\mathrm{AVE}) \geq 0,50$; berarti ukuran kelayakan terpenuhi.

\section{Evaluasi Goodness of Fit (GOF)}

Tujuan evaluasi GOF adalah menguji kesesuaian model dengan data statistik. Berikut ringkasan ukuran kesesuaian model seperti yang ditunjukkan pada Tabel 5.

Tabel 5. Ringkasan Ukuran Kesesuaian Model

\begin{tabular}{|c|c|c|c|}
\hline $\begin{array}{c}\text { Indikator } \\
\text { GoF }\end{array}$ & $\begin{array}{c}\text { Ukuran } \\
\text { yang } \\
\text { Diharapkan }\end{array}$ & $\begin{array}{c}\text { Hasil } \\
\text { Estimasi }\end{array}$ & Kesimpulan \\
\hline Ch-square & $\begin{array}{c}\mathrm{df}=98, \alpha=5 \% \\
<\mathrm{I} 22, \mathrm{II}\end{array}$ & 100,45 & Good Fit \\
\hline $\begin{array}{c}\text { Significancy } \\
\text { Probability }\end{array}$ & $\geq 0,05$ & $0,4 \mathrm{I}$ & Good Fit \\
\hline RMSEA & $<0,08$ & 0,02 & Good Fit \\
\hline GFI & $\geq 0,90$ & 0,90 & Good Fit \\
\hline AGFI & $\geq 0,90$ & 0,86 & Marginal Fit \\
\hline CMIN/DF & $<2,00$ & $\mathrm{I}, 03$ & Good Fit \\
\hline TLI & $\geq 0,95$ & $\mathrm{I}, 00$ & Good Fit \\
\hline CFI & $\geq 0,95$ & $\mathrm{I}, 00$ & Good Fit \\
\hline
\end{tabular}

Sumber: Data primer diolah (2017)

Berdasarkan Tabel 5 ukuran kesesuaian model yang diperoleh hanya AGFI yang marginal fit, sedangkan ukuran lainnya memiliki indeks kesesuaian model yang baik (goodfit), dengan demikian maka dapat dilanjutkan pada analisis berikutnya.

\section{Evaluasi Model Struktural}

Langkah pertama untuk mengevaluasi model struktural adalah melihat covariance matrix dari variabel laten yang menunjukkan nilai korelasi antara konstruk seperti pada Tabel 6.

Tabel 6. Nilai korelasi antar konstruk

\begin{tabular}{|c|c|c|c|c|}
\hline & KEPUASAN & KUALITAS & EM & WOM \\
\hline KEPUASAN & $\mathrm{I}, 00$ & & & \\
\hline KUALITAS & 0,78 & 1,00 & & \\
\hline EM & 0,75 & 0,58 & 1,00 & \\
\hline WOM & 0,79 & 0,59 & 0,74 & $\mathrm{I}, 00$ \\
\hline
\end{tabular}

Sumber: Data primer diolah (2017)

Kemudian untuk melihat signifikansi hubungan jalur antar konstruk maka dilihat thitung jalur seperti pada gambar 4 dan Tabel 7.

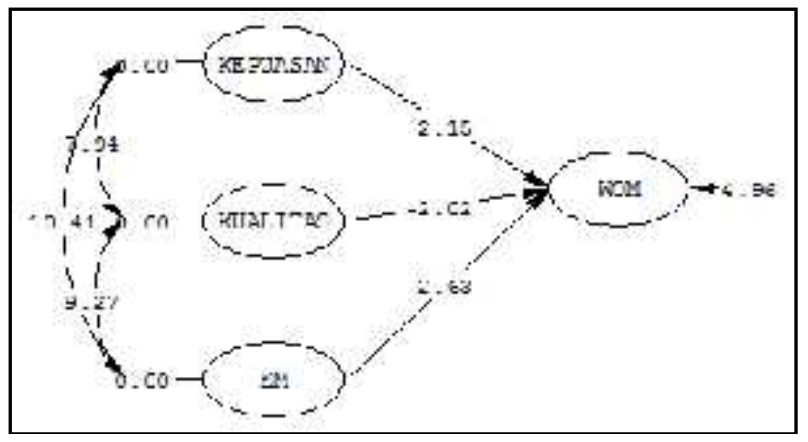

Gambar 4. Structural Model (T-Values) 
Tabel 7. Nilai t-hitung jalur antara konstruk

\begin{tabular}{|l|c|}
\hline \multicolumn{1}{|c|}{ Jalur } & t-hitung \\
\hline KEPUASAN -> WOM & 2,15 \\
\hline KUALITAS -> WOM & 2,02 \\
\hline EM -> WOM & 2,63 \\
\hline
\end{tabular}

Sumber: Data primer diolah (2017)

Berdasarkan Gambar 4 dan Tabel 7 semua nilai t-hitung jalur > 1,96.; maka semua hubungan jalur antar konstruk bersifat signifikan.

Sedangkan nilai koefisien jalur antara konstruk dapat dilihat pada Gambar 5 dan Tabel 8 berikut ini.

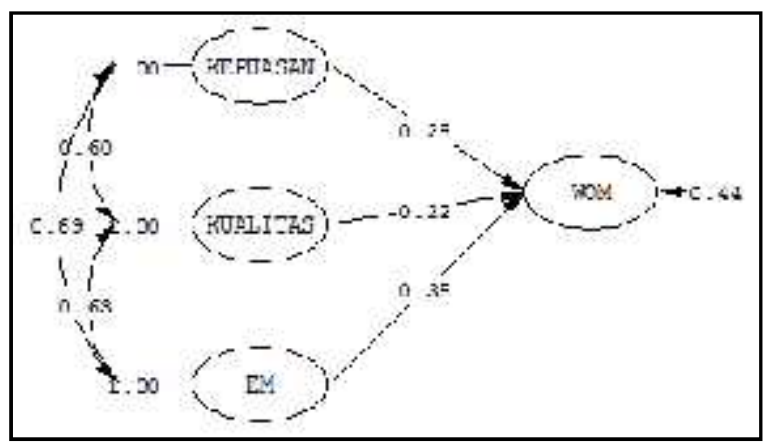

Gambar 5Structural Model (Standardized Solutions)

Tabel 8. Koefisien Jalur Antara Konstruk

\begin{tabular}{|l|c|}
\hline \multicolumn{1}{|c|}{ Jalur } & Koefisien \\
\hline KEPUASAN -> WOM & 0,28 \\
\hline KUALITAS -> WOM & 0,22 \\
\hline EM -> WOM & 0,35 \\
\hline \multicolumn{2}{|c|}{ Sumber: Data primer diolah (2017) } \\
\hline
\end{tabular}

Untuk mendapatkan persentase pengaruh antara konstruk maka koefisien jalur dikalikan nlai korelasi antara konstruk kemudian dikalikan 100\% seperti pada Tabel 9.

Tabel 9. Persentase Pengaruh Antara Konstruk

\begin{tabular}{|l|c|c|c|}
\hline \multicolumn{1}{|c|}{ Jalur } & Koefisien & $\begin{array}{c}\text { Nilai } \\
\text { Korelasi }\end{array}$ & $\begin{array}{c}\text { Persentase } \\
\text { Pengaruh }\end{array}$ \\
\hline KEPUASAN -> WOM & 0,28 & 0,78 & $21.84 \%$ \\
\hline KUALITAS -> WOM & 0,22 & 0,59 & $12.98 \%$ \\
\hline EM -> WOM & 0,35 & 0,74 & $25.90 \%$ \\
\hline
\end{tabular}

Sumber: Data primer diolah (2017)

\section{Pembahasaan}

\section{Pengaruh Kepuasan terhadap Word of Mouth Aplikasi Whatsapp pada Mahasiswa FEB UMT}

Nilai t-hitung hubungan jalur kepuasan terhadap word of mouth sebesar 2,15 > I,96; maka $\mathrm{HI}$ diterima, artinya kepuasan mempunyai pengaruh signifikan terhadap word of mouth aplikasi Whatsapp pada mahasiwa FEB UMT.

Berdasarkan hasil penelitian, kepuasan berpengaruh terhadap word of mouth dengan nilai korelasi sebesar 0,78 yang berarti kepuasan memberikan pengaruh kuat berarah positif terhadap word of mouth aplikasi Whatsapp pada mahasiwa FEB UMT.

Persentase pengaruh kepuasan berpengaruh terhadap word of mouth sebesar $21,84 \%$; berarti kepuasan berkontribusi sebesar $21,84 \%$ terhadap word of mouth aplikasi Whatsapp pada mahasiwa FEB UMT.

Arah hubungan positif kepuasan dengan word of mouth menunjukkan bahwa semakin tinggi kepuasan maka semakin meningkat word of mouth aplikasi Whatsapp pada mahasiwa FEB UMT.

\section{Pengaruh Kualitas terhadap Word of Mouth Aplikasi Whatsapp pada Mahasiswa FEB UMT}

Nilai t-hitung hubungan jalur kualitas terhadap word of mouth sebesar 2,63>1,96; maka $\mathrm{HI}$ diterima, artinya kualitas mempunyai pengaruh signifikan terhadap word of mouth aplikasi Whatsapp pada mahasiwa FEB UMT.

Berdasarkan hasil penelitian, kualitas berpengaruh terhadap word of mouth dengan nilai korelasi sebesar 0,59 yang berarti kualitas memberikan pengaruh sedang berarah positif terhadap word of mouth aplikasi Whatsapp pada mahasiwa FEB UMT.

Persentase pengaruh kualitas berpengaruh terhadap word of mouth sebesar $25,90 \%$; berarti kualitas berkontribusi sebesar $25,90 \%$ terhadap word of mouth aplikasi Whatsapp pada mahasiwa FEB UMT.

Arah hubungan positif kualitas dengan word of mouth menunjukkan bahwa semakin tinggi kualitas maka semakin meningkat word of mouth aplikasi Whatsapp pada mahasiwa FEB UMT.

\section{Pengaruh Experiential Marketing terhadap Word of Mouth Aplikasi Whatsapp pada Mahasiswa FEB UMT}

Nilai t-hitung hubungan jalur experiential marketing terhadap word of mouth sebesar 2,02 $>$ I,96; maka $\mathrm{HI}$ diterima, artinya experiential marketing mempunyai pengaruh signifikan terhadap word of mouth aplikasi Whatsapp pada mahasiwa FEB UMT.

Berdasarkan hasil penelitian, experiential marketing berpengaruh terhadap word of mouth dengan nilai korelasi sebesar 0,74 yang berarti kualitas memberikan pengaruh sedang berarah 
positif terhadap word of mouth aplikasi Whatsapp pada mahasiwa FEB UMT.

Persentase pengaruh experiential marketing berpengaruhb terhadap word of mouth sebesar 12,98\%; berarti kualitas berkontribusi sebesar $12,98 \%$ terhadap word of mouth aplikasi Whatsapp pada mahasiwa FEB UMT.

Arah hubungan positif experiential marketing dengan word of mouth menunjukkan bahwa semakin tinggi experiential marketing maka semakin meningkat word of mouth aplikasi Whatsapp pada mahasiwa FEB UMT.

\section{PENUTUP}

\section{Kesimpulan}

Berdasar hasil penelitian dan pembahasan, maka dapat diambil kesimpulan sebagai berikut:

I. Kepuasan berpengaruh positif signifikan terhadap word of mouth aplikasi whatsapp pada mahasiswa FEB UMT.

2. Kualitas berpengaruh positif signifikan terhadap word of mouth aplikasi whatsapp pada mahasiswa FEB UMT.

3. Experiential marketing berpengaruh positif signifikan terhadap word of mouth aplikasi whatsapp pada mahasiswa FEB UMT.

\section{Saran}

Berdasarkan kesimpulan di atas, dapat dikemukakan beberapa saran yang diharapkan dapat bermanfaat. Adapun saran yang diberikan antara lain:

I. Saran Operasional

Perlu diperhatikan bahwa kinerja word of mouth terkait erat dengan kepuasan, kualitas dan experiential marketing.

2. Saran Akademis

Dalam pengembangan ilmu manajemen pemasaran diharapkan hasil penelitian ini dapat dijadikan acuan agar penelitian berikutmya dapat menggunakan variabel yang sama, metode yang sama tetapi dengan unit analisis berbeda.

\section{DAFTAR PUSTAKA}

Ahad, Annie Dayani and Lim, Syamimi Md Ariff 2014. Convenience or Nuisance?: The 'Whatsapp' Dilemma. Procedia - Social and Behavioral Sciences 155 (p. 189-196).

Al Hamdani, Dawood Salim 2013. Mobile Learning: A Good Practice.Procedia - Social and Behavioral Sciences 103 (p. 665-674)
Andreani, Fransisca. 2007. Experiential Marketing (Sebuah Pendekatan Pemasaran).Jurnal Manajemen Pemasaran, Volume 2 No I. Universitas Kristen Petra Surabaya.

Brown, et al., 2005. Spreading The Words: Investigating Antecedents of Customer's Positive Word of Mouth Intention And Behavior in

Retailing Context,Academy of Marketing Science Journals, Vol.33, no 2, p. I23-138.

Engel, James et al. 2006. Consumer Behaviour. Mason: Permissions Department, Thomson Business and Economics.

Fahima, Lim. 2007. Word of Mouth Kalahkan Pengaruh Iklan ATL. diakses pada tanggal 20 Maret 2018 dari www.virtual.co.id

Feigenbaum, Vallin, Armand. 1992. Kendali Mutu Terpadu. Jakarta: Erlangga.

Ferdinand, Augusty. 2006. Metode Penelitian Manajemen. Edisi 2. Semarang: Badan Penerbit Universitas Diponegoro.

Garvin, David A. (1988). Managing Quality, The New York Press

Gwinner KP, Gremler DD, and Bitner MJ, 1998.

Relational Benefit in Service Industries: The Customer Perspective. Journal Academic Marketing Science, Vol. 26, pp. I0I-I I4.

Harrison, L. Jean-Walker. 200I. The Measurement Of Word Of Mouth Communication And An Investigation Of Service Quality And Customer Commitment As Potential Antecedents. Journal of Service Research,Vol. 4, No. I, pp. 6075.

Herr, P.M., Kardes, F.R. and Kim, J. 1991 Effects of word-of- mouth and product attribute information on persuasion: an accessibilitydiagnosticity perspective. Journal of Consumer Research 17, 454- 62.

Kartajaya, Hermawan. 2002. Hermawan Kartajaya On Marketing. Jakarta: PT. Gramedia Pustaka Utama.

Kotler, Philip. 200I. Manajemen Pemasaran: Analisis, Perencanaan, Implementasi, dan Kontrol. Jakarta : PT. Prehallindo.

Nuys, David Van. 2005. The Viral Impact of Experiental Marketing. Event Marketer Magazine E-Focus Group. 
Parasuraman, A. A. Zeithaml, V., and L. Berry, L. 1995. A Conceptual Model of

Service Quality and Its Implications for Future Research. Journal of Marketing. Vol. 49 (fall)

Peter, J. Paul dan Jerry C Olson. 2002. Perilaku Konsumen dan Strategi Pemasaran. Terjemahan. Jakarta: Erlangga.

Priharmoko, Patria. 2004. Faktor-faktor yang mempengaruhi Word of Mouth pada konsumen Studi kasus pelanggan kartu halo DKI Jakarta. Tesis. Universitas Indonesia. Depok.

Rangkuti, Freddy. 2002. Measuring Customer Satisfaction Teknik Mengukur dan Strategi Meningkatkan Kepuasan Pelanggan dan Analisis Kasus PLNJP. PT. Gramedia Pustaka Utama, Jakarta.

Schmitt, Bernd H, 1999. Experiential Marketing: how to get your customers to sense, feel, think, act, and relate to your company and brand. The Free Press.

Sugiyono. 2013. Metode Penelitian Kuantitatif Kualitatif dan R \& D. Bandung: Alfabeta.

Supomo, Bambang dan Indriantoro, Nur. 2002. Metodologi Penelitian Bisnis, Cetakan Kedua. Yogyakarta: Penerbit BFEE UGM.

Thomas, Greg Metz. 2004. Bulding The Buzz In The Hive Mind. Journal of Consumer Behavior: Oct 2004; 4, I: ABI/INFORM Global.

Tjiptono, Fandy. 2006. Manajemen Jasa. Edisi Pertama. Yogyakarta : Andi.

Wagner, J. and G. Rydstrom. 200I. Satisfaction, trust, and commitment in consumer relationship with online retailer. European Advances in Consumer Research. 5. 276-28I.

Wijanto, Setyo Hari. 2008. Structural Equation Modeling dengan LISREL 8.8. Yogyakarta: Graha Ilmu.

Zeithaml. 1990. Delivering Quality Service. New York: Mc Graw Hil. 